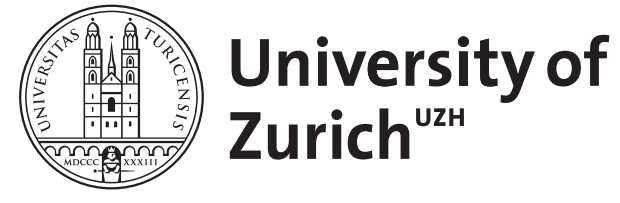

Zurich Open Repository and Archive

University of Zurich

Main Library

Strickhofstrasse 39

CH-8057 Zurich

www.zora.uzh.ch

Year: 2007

\title{
When grief becomes a disorder
}

Maercker, Andreas

DOI: https://doi.org/10.1007/s00406-007-0742-2

Posted at the Zurich Open Repository and Archive, University of Zurich

ZORA URL: https://doi.org/10.5167/uzh-66066

Journal Article

Published Version

Originally published at:

Maercker, Andreas (2007). When grief becomes a disorder. European Archives of Psychiatry and Clinical Neuroscience, 257(8):435-436.

DOI: https://doi.org/10.1007/s00406-007-0742-2 


\section{Andreas Maercker \\ When grief becomes a disorder}

Published online: 13 November 2007

It has long been discussed that the grief over losing a close person can become a mental illness. Erich Lindemann (1944) provided us with both a first precise description of normal grief and a description of various pathological grief reactions, which he had identified among the survivors and bereaved relatives of a serious nightclub fire in Boston (Coconut Grove Fire). He described persistently altered patterns of experience, action, and relationships in some of these people. Lindemann's account was a great success in psychiatry and gave rise to much subsequent work.

Parallel to this early literature on causes of grief and depression v. Baeyer, Häfner \& Kisker (1964) and others found persistent and severe depression not only after loss of significant others but especially after a long lasting stay in the concentration camps of the National Socialist regime. The authors introduced the diagnostic concept of "chronic depression" with persistent grief, anxiety, depressed mood, social impairment frequently spanning over decades or lifetime. These diagnoses and etiological concepts were also introduced into the legal context of German compensation laws.

These earlier conceptualizations were precursors to current views about normal and abnormal grief, which are still largely based on clinical observations, albeit with greater attention to the systematic collection of data. In this regard, very different causes of grief or circumstances surrounding deaths are examined, such as violent death, death due to illness or expected, sudden, or unexpected deaths, and the

\footnotetext{
A. Maercker, M.D., Ph.D. ( $\square)$

Div. of Psychopathology \& Clinical Intervention

University of Zurich

Binzmühlestr. 14, Box 17

8050 Zurich, Switzerland

Tel.: +41-44/635-7310

Fax: +41-44/635-7319

E-Mail: maercker@psychologie.uzh.ch
}

death of unborn babies, children, adolescents, siblings, spouses, and other loved ones.

In the ICD-10 and DSM-IV-TR, grief is recognized as a clinical problem, although both classification systems categorize abnormal consequences of grief as belonging to other existing disorder categories. In ICD-10, the diagnosis of an adjustment disorder is recommended for abnormal grief reactions (possibly as a prolonged depressive reaction, F43.21), with reference also being made to the Z-chapter (e.g. disappearance or death of a family member, Z63.4) as an additional possibility for description. The DSM-IVTR recognizes that typical depression symptoms are common after the loss of a loved one but that Major Depressive Disorder should only be diagnosed when the symptoms persist for more than 2 months or include marked functional impairment, morbid preoccupation with guilt, suicidal ideation, or psychomotor retardation. Grief or bereavement is included in the $\mathrm{V}$-chapter on other clinically relevant problems (V62.82). Thus, the current official psychiatric nomenclature does not recognize chronic grief reactions as an independent entity.

In the last decade, some investigators studying persons who have persistent symptoms and impairment following bereavement have concluded that there is a syndrome of chronic abnormal grief (also called complicated grief). The earliest described diagnostic algorithm for complicated grief according to Horowitz et al. (1997) has been shown to differentiate patients suffering from grief from patients with Major Depressive Disorder. Prigerson et al. (1999), whose group described the other new diagnostic conceptualization, demonstrated that the symptoms of disordered grief form a factor that is distinct from factors of depression and anxiety. Characteristic features of both concepts include persisting preoccupation with thoughts about the lost person along with yearning, longing, inability to ac- 
cept the death, distressing intrusive thoughts about the death, and avoidance of reminders of the loss. These two concepts have since been examined together for a diagnosis of chronic abnormal grief and presented as a consensus for the development of the DSM-V and ICD-11.

The growing research regarding a grief disorder that is separate from depression, anxiety, and adjustment disorders continues to be faced with some crucial questions. First, when does the transition from normal to abnormal grief occur (or from grief consequences that can be coped with spontaneously to those requiring therapy)? Second, what risk factors lead to the emergence, from a chronically abnormal grief reaction, of additional disorders such as Major Depressive Disorder, or somatoform disorders, which can also occur in this context? A multitude of risk factors are possible in each case here, including, besides the actual circumstances of the death, the individual meaning of the loss or of the previous relationship with the deceased, the individual's coping resources, and social support.

In the contributions to the current Special Section, an attempt will be made to provide answers to these questions. Kersting et al. (this issue) examine the presence of symptoms of complicated grief (e.g. intrusions and avoidance) in mothers with induced termination of pregnancy from a longitudinal perspective up to 14 months after the event. They found that after this lengthy period of time, approximately a quarter of those investigated were critically affected by the loss, with over $10 \%$ of patients showing a direct diagnosis of complicated grief (CG) and less then $20 \%$ having developed (alone or additionally) another psychiatric diagnosis (e.g. depressive or anxiety disorders). They were able to identify a series of risk factors and protective factors for CG, the strongest of which was the social support after 6 months.

Using a representative sample of mourners with the most frequently occurring causes of death (e.g. illness, accident, death of spouse through old age, death of children or parents), Boelen and Prigerson (this issue) examine the influence of abnormal grief symptoms as well as depressions and anxiety symptoms on quality of life and general mental health course up to 15 months after the bereavement. As expected, the influence of the abnormal grief symptoms on the state of mental and physical (e.g. pain) health was greater than the influence of depressive or anxiety symptoms.
Together with her colleagues, Shear, who is one of today's most prominent experts in the treatment of grief, addresses the problem of the transition from normal grief to abnormal or complicated grief (this issue). They focus on the importance of previously existing attachment patterns between the patient and the deceased (which, indeed, are examined as risk factors in a series of mental disorders), which are assumed to play a very prominent role in complicated grief. Two different coping styles are described, namely loss-focused strategies and restoration-focused strategies, and it is shown that these are accompanied by differing extents of avoidance behavior.

Along with her Dutch team of co-authors, Stroebe also concentrates on the transition from normal to abnormal grief. Their model ties in with the psychoanalytical concept that "grief work", i.e. confronting or reflecting on the loss is the best and only way to avoid developing pathological grief reactions. The authors differentiate the meaning of so-called working through of the loss. They argue that ruminative thoughts on the death do not possess any healing value; rather through their focus on negative emotions, they should instead be seen as cognitive avoidance processes. The way in which somebody deals with the loss of a person therefore plays a role in determining whether chronically abnormal grief will occur. Finally, a word on the terminology used: Some of the authors describe the "new" disorder as complicated grief disorder, while others use the term prolonged grief disorder. In the last few years, the term of traumatic grief disorder has also been found in the literature. This should not lead to confusion when reading the contributions. The terminology and descriptions and the finer points thereof that ultimately win through can be left to the new clinical and scientific findings that will emerge in the near future.

\section{References}

1. Horowitz MJ, Siegel B, Holen A, Bonanno GA, Milbrath C, Stinson CH (1997) Diagnostic criteria for complicated grief disorder. Am J Psychiatry 154:904-910

2. Prigerson HG, Shear MK, Jacobs SC, Reynolds CF, Maciejewski PK, Davidson JRT, et al. (1999) Consensus criteria for traumatic grief: A preliminary empirical test. Br J Psychiatry 174: $67-73$ 